\title{
Antenatal Betamethasone Administration Has a Dual Effect on Adult Sheep Vascular Reactivity
}

\author{
VICTOR M. PULGAR AND JORGE P. FIGUEROA
}

Center for Research in Obstetrics and Gynecology, Department of Obstetrics and Gynecology, Wake Forest University School of Medicine, Winston-Salem, North Carolina 27157

\begin{abstract}
The effect of antenatal steroids on blood pressure in humans remains an unresolved question. Here we report the effects of prenatal exposure to clinically relevant doses of betamethasone on endothelial and/or vascular smooth muscle function. Pregnant sheep were randomly treated with betamethasone $(0.17 \mathrm{mg} / \mathrm{kg})$ or vehicle at 80 and $81 \mathrm{~d}$ of gestation. We studied arterial segments (4th-5th generation) of the right brachial artery obtained at 1-2 y of age under general anesthesia. We demonstrate that in brachial arteries of steroid exposed offspring: $\mathrm{KCl}$ induced contraction is increased after endothelium removal or incubation with inhibitors of nitric oxide synthase or cyclooxygenase; acetylcholine-induced relaxation is increased; sensitivity to endothelin-1 (ET-1) is increased and this effect is decreased by the $\mathrm{ET}_{\mathrm{B}}$ antagonist $\mathrm{BQ}-788$. These data suggest that, in sheep treated with clinically relevant doses of betamethasone at a gestational stage when human fetuses are routinely exposed to glucocorticoids, there is a dual effect of betamethasone on the adult sheep brachial artery, i.e. endothelial dysfunction with an impairment of endothelin-1 $\mathrm{ET}_{\mathrm{B}}$ receptor-induced release of nitric oxide and an increased contribution of the $\mathrm{ET}_{\mathrm{B}}$ receptor in smooth muscle to the contractile effects of ET-1. (Pediatr Res 60: 705-710, 2006)
\end{abstract}

$\mathrm{E}$ pidemiologic and experimental evidence strongly suggest that some adult-onset disease conditions may have their origin in fetal life (1). Evidence from animal models of fetal programming indicates that antenatal glucocorticoids have adverse cardiovascular effects in the adult offspring, with alterations in vascular reactivity being a common finding in animal models across several species. In sheep, antenatal exposure to dexamethasone at $27-28$ dGA results in adult hypertension and alterations in mesenteric artery vascular reactivity in 123-126 dGA fetuses, and in coronary reactivity in 1-wk-old and 4-mo-old lambs $(2,3)$. Repeated weekly exposure to low doses of dexamethasone starting at $103 \mathrm{dGA}$ does not produce changes in blood pressure, but it does alter femoral artery sensitivity to ET-1 and to acetylcholine (ACh) in 5-mo-old lambs (4).

We have recently shown that treating pregnant sheep with clinically relevant doses of betamethasone at $80 \mathrm{dGA}$ is associated with a lowering in the number of nephrons in

Received April 28, 2006; accepted August 12, 2006.

Correspondence: Jorge P. Figueroa, M.D., Ph.D., Department of Obstetrics and Gynecology, Wake Forest University School of Medicine, Medical Center Boulevard, Winston-Salem, NC 27157; e-mail: figueroa@wfubmc.edu

This study was funded by National Institutes of Health (grant no. HL68728).

DOI: 10.1203/01.pdr.0000246481.05231.17 fetuses at $135 \mathrm{dGA}$ and a significant increase in arterial blood pressure in 6-mo-old young adult sheep (5) and in 1-2-y-old adult sheep (Shaltout $\mathrm{H}$ et al., Antenatal Betamethasone Causes Angiotensin II-Mediated Impairment of Cardiovascular Function, 60th Annual Fall Conference Council for High Blood Pressure Research, October 4-7, 2006, San Antonio, TX, unpublished observations). Importantly, in humans, an association between antenatal glucocorticoid administration and elevations in systolic and diastolic blood pressure at $14 \mathrm{y}$ of age has been reported (6). A decrease in nephron number is also a common finding in animal models of fetal programming, however, the magnitude of the reduction in nephron mass cannot by itself explain the development of hypertension $(7,8)$. Several contributing factors for the development of hypertension have been proposed, i.e. increases in cardiac output (9), in sodium retention $(10,11)$, in sympathetic outflow (12), and altered vascular reactivity $(2,3)$. ET-1 is the main endothelin generated in the endothelium and induces vasoconstriction, cell proliferation, and hypertrophy through the stimulation of smooth muscle $\mathrm{ET}_{\mathrm{A}}$ receptors and vasorelaxation through stimulation of endothelial $\mathrm{ET}_{\mathrm{B}}$ receptors (13). Recently, more attention has been given to the possibility that alterations in the endothelin system may contribute to the development of hypertension in humans $(14,15)$.

The aim of the present study was to determine whether prenatal exposure to clinically relevant doses of betamethasone is associated with alterations in endothelial and/or smooth muscle function that are likely to be expressed as abnormal vascular reactivity in adult sheep by studying a subset of the animals in which we have documented an elevation in arterial blood pressure (5).

\section{MATERIALS AND METHODS}

\begin{abstract}
Animals. Sixteen date-mated pregnant sheep were randomly assigned to receive betamethasone or vehicle. Pregnant sheep received two intramuscular doses of $0.17 \mathrm{mg} / \mathrm{kg}$ of a $1: 1 \mathrm{mixture}$ of betamethasone acetate and betamethasone phosphate [Celestone Soluspan, Schering, Kenilworth, $\mathrm{NJ}(n=8)$ ] or vehicle $(n=8)$ given $24 \mathrm{~h}$ apart at 80 and $81 \mathrm{~d}$ of gestation. Sheep were maintained with free access to food and water in open pasture throughout the entire pregnancy and offspring raised by the mother until weaned at 3 mo of age. Adult offspring of both sexes were euthanized under halothane general anesthesia at 1-2 y of age to obtain 4th and 5th generation segments of the right brachial artery. All procedures were approved by the Institutional Animal Care and Use Committee.
\end{abstract}

Abbreviations: dGA, days of gestational age; ET-1, endothelin-1 
Arterial segment preparation. Under a dissecting microscope, the right brachial artery was dissected and followed until arteries of approximately 200 $\mu \mathrm{m}$ in diameter were identified. Arteries were dissected free of surrounding tissue, cut into 1.5-2 mm segments, and mounted between an isometric force transducer (Kistler Morce DSC 6, Seattle, WA) and a displacement device on a myograph (Multi Myograph, Model 610M Danish Myo Technologies, Aarhus, Denmark) using two stainless steel wires (diameter $40 \mu \mathrm{m}$ ). The myograph organ bath $(5 \mathrm{~mL})$ was filled with Krebs-Henseleit buffer (KHB) maintained at $37^{\circ} \mathrm{C}$ and aerated with $95 \% \mathrm{O}_{2}-5 \% \mathrm{CO}_{2}$. The vessels were washed and incubated for $30 \mathrm{~min}$ before obtaining the optimal diameter. Each arterial segment was stretched to its individual optimal lumen diameter, following the normalization procedure previously described (16). For preliminary calculations of wall tension, arteries were stretched in a stepwise manner, and the internal circumference and corresponding wall tension as a result of each stretch were calculated and plotted to produce a resting wall tension-internal circumference curve for that particular artery. Our preliminary studies showed that maximum contractile force to $62.5 \mathrm{mM} \mathrm{KCl}$ was observed at $0.9 \mathrm{~L}_{100}$. This normalization has been shown to be the optimal calibration method for studies of peripheral vessels (16). In all studies, after obtaining the optimal diameter, a 30 -min equilibration preceded the addition of test substances.

Response to depolarizing concentrations of $\mathbf{K C l}$. An escalating concentration-response curve was constructed for $\mathrm{KCl}$ by exposing the arteries to 11 different concentrations of $\mathrm{KCl}(4.75-113 \mathrm{mM})$ with each dose maintained for 2 min and the segment washed with $\mathrm{KBH}$ before the subsequent concentration was introduced. In parallel experiments, different arterial segments were endothelium-denuded or preincubated for 15 min with either $100 \mu \mathrm{M}$ L-NAME or with $10 \mu \mathrm{M}$ indomethacin. The endothelium was disrupted by passing a human hair through the lumen of the vessel and the effectiveness of the procedure confirmed by evaluating the response of each vessel to ACh.

Response to ACh. A cumulative concentration-response curve for acetylcholine was constructed by adding 13 different concentrations (ACh $10^{-11}$ $10^{-5} \mathrm{M}$ ) to vessels preconstricted with $40.8 \mathrm{mM} \mathrm{KCl}$ and each subsequent dose being introduced at 2-min intervals. In parallel experiments, different arterial segments were preincubated for 15 min with either $100 \mu \mathrm{M}$ L-NAME or with $10 \mu \mathrm{M}$ indomethacin before being exposed to the same concentrations of ACh.

Response to ET-1. A cumulative concentration-response curve was constructed for ET-1 by exposing arteries to seven half-log $\left(10^{-11}-10^{-7} \mathrm{M}\right)$ increasing concentrations with each subsequent dose being introduced after a steady response had been reached. In parallel experiments, different arterial segments were endothelium-denuded or preincubated for $15 \mathrm{~min}$ with either $100 \mu \mathrm{M}$ L-NAME or $10 \mu \mathrm{M}$ indomethacin. Also, additional arterial segments were preincubated for 30 min either the $\mathrm{ET}_{\mathrm{A}}[\mathrm{BQ123}(1 \mu \mathrm{M})]$ or the $\mathrm{ET}_{\mathrm{B}}$ [BQ788 $(1 \mu \mathrm{M})]$ receptor antagonists before exposed to the same ET-1 doses.

Solutions and drugs. Krebs-Henseleit buffer contained (in $\mathrm{mM}$ ) $\mathrm{NaCl}$ 118.5, $\mathrm{NaHCO}_{3} 25, \mathrm{KCl} 4.7, \mathrm{KH}_{2} \mathrm{PO}_{4} 1.2, \mathrm{MgSO}_{4} 1.2, \mathrm{CaCl}_{2} 2.5$, and glucose 5.5 with a final $\mathrm{pH}$ of 7.4. In solutions used for testing $\mathrm{KCl}$ depolarizing effects, $\mathrm{NaCl}$ was replaced by an equimolar amount of $\mathrm{KCl}$. All drugs used were obtained from Sigma Chemical Co. (St. Louis, MO).

Data analysis. Concentration-response curves were analyzed by fitting individual experimental data to a sigmoid to determine maximal response and

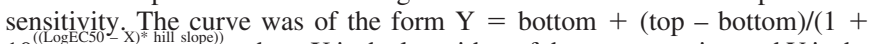
$10^{\left.(\operatorname{LogEC50}-\mathrm{X})^{*} \text { hill slope) }\right)}$, where $\mathrm{X}$ is the logarithm of the concentration and $\mathrm{Y}$ is the response. The contractile response to $\mathrm{KCl}$ was expressed in units of arterial wall tension in $\mathrm{mN} / \mathrm{mm}$ and the response to ET- 1 was expressed as percentage of the maximal response to $\mathrm{KCl}$. Relaxant responses were expressed as the percentage of reduction of $\mathrm{KCl}$-induced contraction. Sensitivity defined as $\mathrm{EC}_{50}$ was expressed as $\mathrm{pD}_{2}=-\log$ [EC50]. The ET-1 response in the presence of L-NAME was normalized using the arterial segment's response to $\mathrm{KCl}$ following L-NAME incubation, and in vessels preincubated with the receptor antagonists $\mathrm{BQ788}$ or $\mathrm{BQ} 123$ data were normalized using the maximal response to $\mathrm{KCl}$. Data are shown as mean \pm SEM.

Statistical analysis. The study was designed to compare the effects of antenatal betamethasone (BM) on vascular reactivity. Therefore, a priori we established that statistical differences would be evaluated using the twosample $t$ test to compare control versus BM-treated, and were considered significant if $p<0.05$. Sample size refers to the number of animals. Where more than one segment per artery was tested for a given agonist, the data were averaged.

\section{RESULTS}

There was no significant difference in the calculated optimal internal diameter between arteries obtained from the control and the betamethasone exposed groups (control: $366 \pm 10$ $\mu \mathrm{m} ; n=8$ versus $\mathrm{BM}$ : $373 \pm 9 \mu \mathrm{m} ; n=8$ ). As shown in Table 1, no significant differences in sex distribution, age, or body weight between sheep in control and the betamethasone groups were present.

Response to depolarizing concentrations of $\mathbf{K C l}$. No differences in the response to depolarizing potassium-containing solutions were observed when comparing intact arteries of control and betamethasone-treated animals (Fig. 1A). Values for sensitivity expressed as $\mathrm{pD}_{2}(1.4 \pm 0.02$ versus $1.5 \pm$ $0.02)$ or maximal response $(7.5 \pm 0.24$ versus $7.8 \pm 0.22$ $\mathrm{mN} / \mathrm{mm}$ ) were virtually identical. In endothelium-denuded arteries, the maximal response to $\mathrm{KCl}$ was significantly higher in arteries of the BM group (Fig. 1B). The maximal response was $8.5 \pm 0.24 \mathrm{mN} / \mathrm{mm}$ in the control group and $10.5 \pm 0.65$ $\mathrm{mN} / \mathrm{mm}$ in the BM group $(p<0.05)$, whereas no differences were observed in the $\mathrm{pD}_{2}$ value $(1.4 \pm 0.03$ versus $1.4 \pm$ 0.03). A higher contractile response in $\mathrm{BM}$ arteries was also evident in arteries preincubated with $10 \mu \mathrm{M}$ indomethacin $6.6 \pm 0.5 \mathrm{mN} / \mathrm{mm}$ versus $9.9 \pm 1.3 \mathrm{mN} / \mathrm{mm}$ ( $p<0.05$; Fig. $1 C)$ and in arteries preincubated with $100 \mu \mathrm{M}$ L-NAME $9.1 \pm 0.52 \mathrm{mN} / \mathrm{mm}$ versus $16.1 \pm 1.59 \mathrm{mN} / \mathrm{mm}(p<0.05$; Fig. $1 D)$. Preincubation with either indomethacin or L-NAME did not affect the $\mathrm{pD}_{2}$ values of arterial segment responses to $\mathrm{KCl}$ in either group.

Response to ACh. The role of endothelium-dependent relaxation evaluated by exposing the arterial segment to ACh revealed a higher maximal relaxation $(70 \pm 5.1 \%$ versus $47 \pm$ $6.8 \%, p<0.05)$ and a greater sensitivity $(7.7 \pm 0.31$ versus $6.5 \pm 0.23, p<0.05$ ) in arteries from the BM group (Fig. 2). This relaxing response was significantly reduced in both groups by preincubation with either $100 \mu \mathrm{M}$ L-NAME to $20 \pm 7 \%$ in BM and to $7 \pm 7 \%$ relaxation in controls (Fig. 2) or $10 \mu \mathrm{M}$ indomethacin to $48 \pm 3 \%$ in $\mathrm{BM}$ and to $16 \pm 7 \%$ relaxation in controls (Fig. 2).

Response to ET-1. Exposure of arterial segments to increasing concentrations of ET-1 resulted in a concentrationdependent contraction in both the control and BM group (Fig. 3 ). While the sensitivity to ET-1 was significantly higher in the arteries of BM-treated animals $(8.2 \pm 0.05$ versus $7.8 \pm$ $0.08, p<0.05$ ), no differences in maximal response were observed. As shown in Figure 4A, removal of the endothelium significantly increased the maximal response to ET-1 in arteries obtained from the control group $(155 \pm 1.7$ versus $119 \pm$ $5.1 \%, p<0.05$ ), but did not modify the response to ET-1 in arteries of the BM group (Fig. $4 B$ ). Similarly, pre incubation with L-NAME significantly increased the maximal response to ET-1 in arteries of the control group (Fig. $4 C, 165 \pm 17.5$ versus $119 \pm 5.1 \%, p<0.05$ ), without having an effect on the response to ET-1 in arteries of the BM group (Fig. $4 D$ ). Preincubation with indomethacin did not alter the response to ET-1 in either group (data not shown).

Table 1. Sample size and animal characteristics

\begin{tabular}{lcccccc}
\hline & No. & Female & Male & Age (y) & Weight $(\mathrm{kg})$ & Twins \\
\hline Control & 8 & 4 & 4 & $1.8 \pm 0.1$ & $68.5 \pm 4$ & 7 \\
Betamethasone & 8 & 3 & 5 & $1.7 \pm 0.1$ & $66.6 \pm 3$ & 7 \\
\hline
\end{tabular}



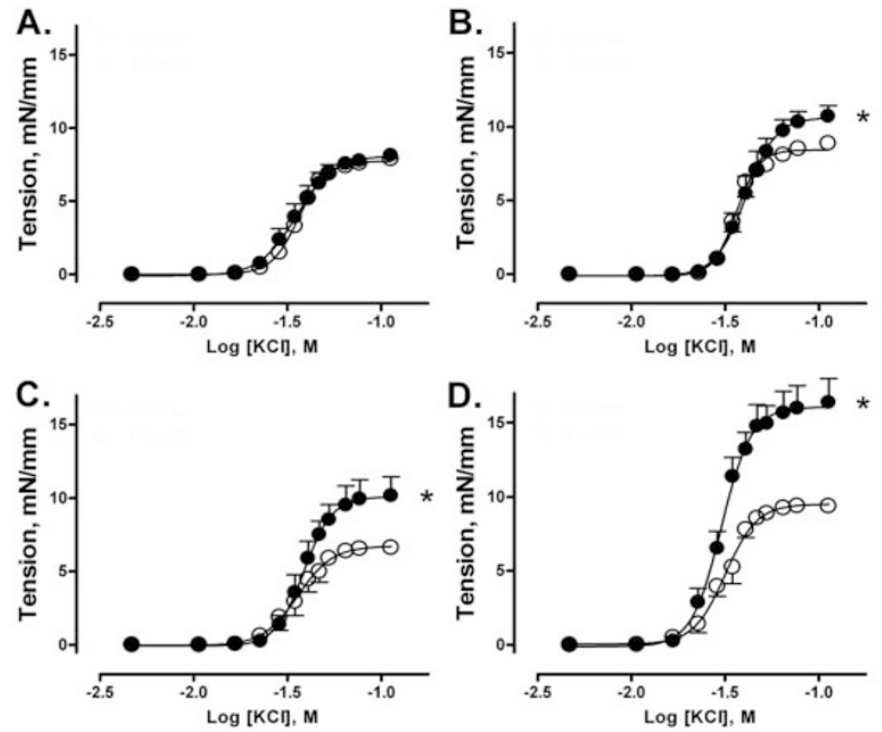

Figure 1. Potassium chloride $(\mathrm{KCl})$-induced vasoconstriction in brachial arteries from control $(O)$ and betamethasone-treated $(\bullet)$ adult sheep. Responses are expressed as absolute values of tension in $\mathrm{mN} / \mathrm{mm}$. (A) Intact arteries (control, $n=8$; treated, $n=8$ ); $(B)$ arteries without endothelium (control, $n=5$; treated, $n=5$ ); $(C)$ intact arteries preincubated with $10 \mu \mathrm{M}$ indomethacin (control, $n=7$; treated, $n=7$ ); $(D)$ intact arteries preincubated with $100 \mu \mathrm{M}$ L-NAME (control, $n=7$; treated, $n=7$ ). Data are shown as mean \pm SEM. ${ }^{*} p<0.05$ in maximal response by two-sample $t$ test.

The endothelin $\mathrm{ET}_{\mathrm{B}}$ receptor antagonist BQ-788 $\left(10^{-6} \mathrm{M}\right)$ produced a leftward displacement of the ET-1 concentration response curve in control arteries reflecting a significant increase in the sensitivity from $7.8 \pm 0.08$ to $8.3 \pm 0.09(p<$ 0.05 ) without affecting the maximal response (Fig. $5 A$ ). In contrast, in arteries of BM-treated sheep preincubation with BQ-788 $\left(10^{-6} \mathrm{M}\right)$ resulted in a rightward displacement of the ET-1 concentration response curve, reflecting a significant decrease in the sensitivity from $8.2 \pm 0.05$ to $7.8 \pm 0.10(p<$ 0.05 ) also without affecting the maximal response (Fig. $5 B$ ). The effect of the $\mathrm{ET}_{\mathrm{A}}$ receptor antagonist BQ-123 at $10^{-6} \mathrm{M}$ was a rightward displacement of the concentration response curve and a reduction in the maximal response to ET-1 in both control and BM-treated sheep (Fig. 5, $C$ and D). Although a significant reduction in maximal response was observed in the
A.

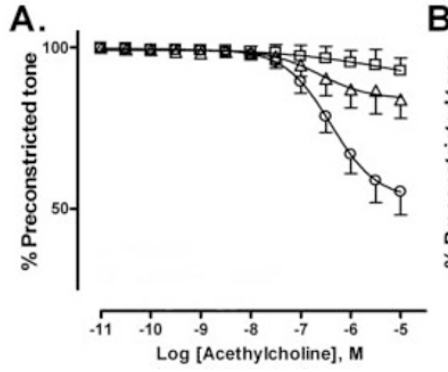

B.

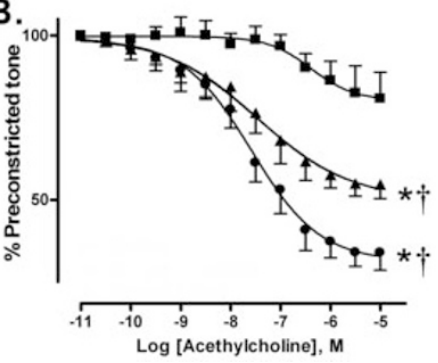

Figure 2. ACh-induced relaxation in control (open symbols) and betamethasone-treated (closed symbols) adult sheep preconstricted brachial arteries. Responses are expressed as percentage of the contraction response to 40.8 $\mathrm{mM} \mathrm{KCl}$. (A) Control baseline $(\bigcirc, n=8)$; control indomethacin $(\triangle, n=5)$; control L-NAME ( $\square, n=5)$. (B) BM-treated arteries $(\bullet, n=8)$; indomethacin $(\boldsymbol{\Lambda}, n=5)$; L-NAME $(\boldsymbol{\square}, n=5)$. Data are shown as mean \pm SEM. $* p<0.05$ in maximal response; $\dagger p<0.05$ in sensitivity by two-sample $t$ test.

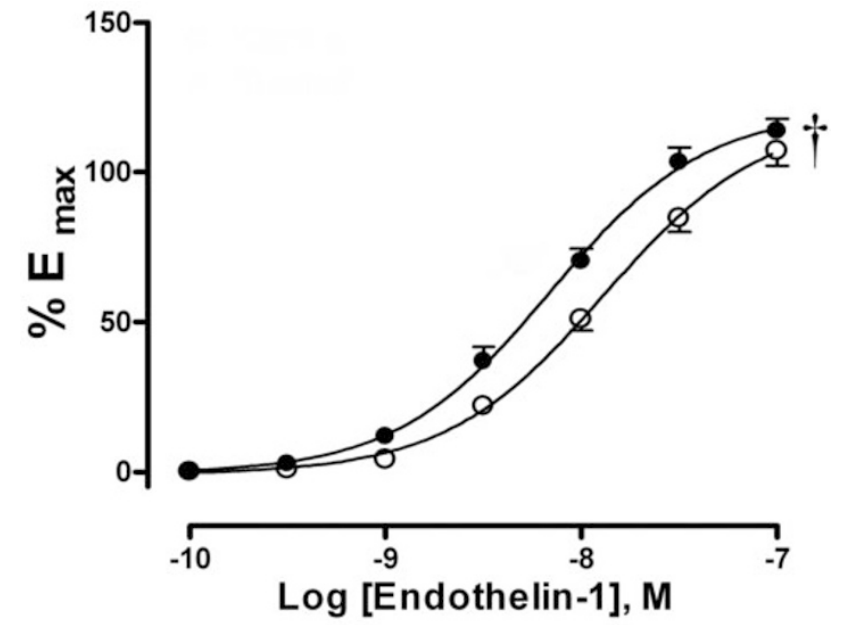

Figure 3. Response to endothelin-1 in brachial arteries of control $(\bigcirc, n=8)$ and betamethasone-treated $(\bullet, n=8)$ adult sheep. Responses are expressed as percentage of maximal response to potassium chloride (\% Emax). Data are shown as mean \pm SEM. $\dagger p<0.05$ in sensitivity by two-sample $t$ test.

control group $(125.6 \pm 6.8$ versus $89.2 \pm 7 \% p<0.05)$ and the BM-exposed group (BM $119 \pm 5.1$ versus $95 \pm 3.4 \% p<$ $0.05)$, the change in sensitivity was significant only for the BM group.

\section{DISCUSSION}

The aim of the study was to ascertain the effects of antenatal steroid treatment on the contractile responses of small muscle arteries of adult sheep. These animals represent a subset of a cohort in which an elevation in blood pressure was evident at either 6 mo of age (5) or 1-2 y of age (Shaltout $\mathrm{H}$ et al., Antenatal betamethasone causes angiotensin II-mediated im-
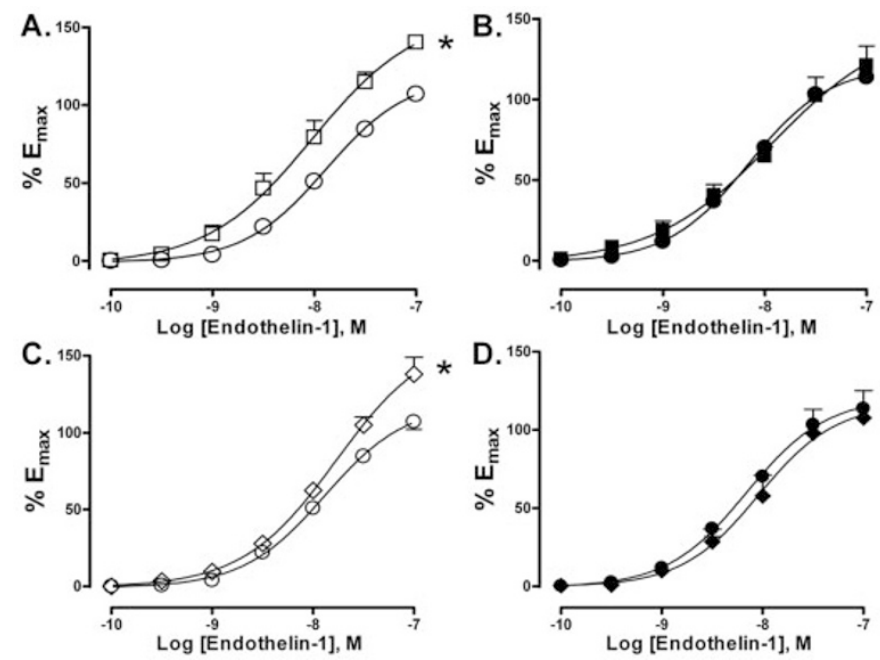

Figure 4. Role of endothelium and nitric oxide production on the ET-1 response of control (open symbols) and betamethasone-exposed (closed symbols) adult sheep brachial arteries. (A) Control intact endothelium $(\bigcirc, n=8)$; endothelium denuded ( $\square, n=5$ ) arteries. (B) BM-treated endothelium intact $(\bullet, n=8)$; endothelium-denuded $(\boldsymbol{\square}, n=5)$. (C) Control baseline $(\bigcirc, n=$ 8); L-NAME $(\diamond, n=5)$. ( $D$ ) BM-treated baseline $(\bullet, n=8)$; L-NAME $(\bullet$, $n=5$ ). Responses are expressed as percentage of maximal response to potassium chloride $\left(\% \mathrm{E}_{\max }\right)$. Data are shown as mean \pm SEM. ${ }^{*} p<0.05$ in maximal response by two-sample $t$ test. 

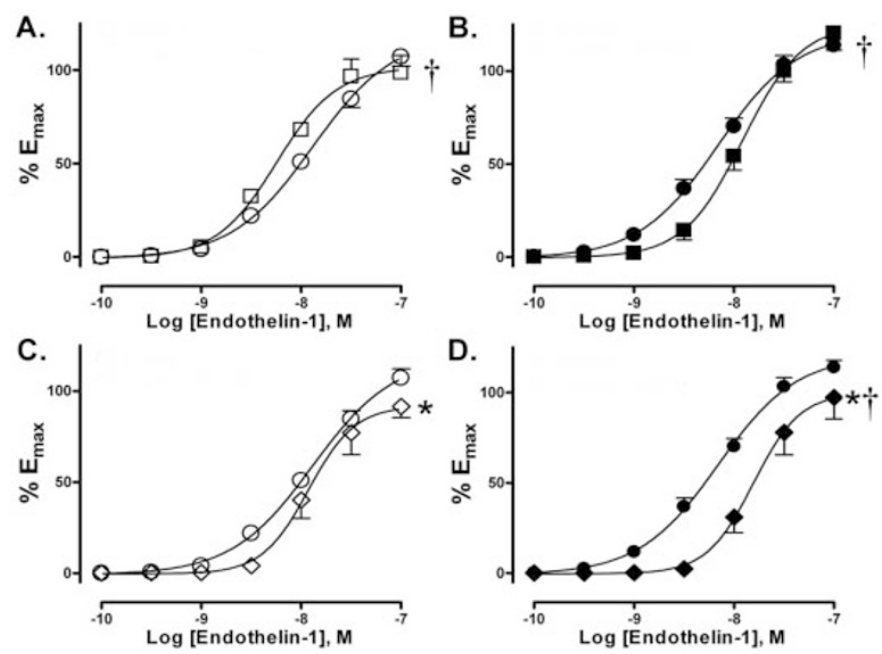

D.

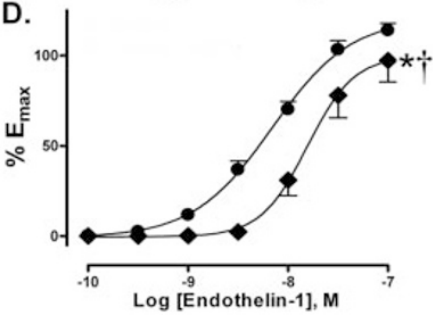

Figure 5. Effect of blocking endothelin receptors on the ET-1 response in control (open symbols) and betamethasone-exposed (closed symbols) adult sheep brachial arteries. (A) Control baseline $(\mathrm{O}, n=8)$; $\mathrm{ET}_{\mathrm{B}}$ receptor blocker BQ788 $10^{-6} \mathrm{M}(\square, n=3)$. (B) BM-treated baseline $(\bullet, n=8)$; BQ788 $10^{-6}$ $\mathrm{M}(\mathbf{\square}, n=3)$. (C) Control baseline $(\mathrm{O}, n=8)$; $\mathrm{ET}_{\mathrm{A}}$ receptor blocker $\mathrm{BQ} 123$ $10^{-6} \mathrm{M}(\diamond, n=3)$. (D) BM-treated baseline $(\bullet, n=8)$; BQ123 $10^{-6} \mathrm{M}(\diamond$, $n=3$ ). Responses are expressed as percentage of maximal response to potassium chloride $\left(\% \mathrm{E}_{\max }\right)$. Data are shown as mean \pm SEM. $* p<0.05$ for maximal response; $\dagger p<0.05$ for sensitivity tested by two-sample $t$ test baseline $v s$ receptor blocker.

pairment of cardiovascular function, 60th Annual Fall Conference Council for High Blood Pressure Research, October 4-7, 2006, San Antonio, TX, unpublished observations). Special emphasis was given to the role of endothelin- $1 \mathrm{ET}_{\mathrm{A}}$ and $\mathrm{ET}_{\mathrm{B}}$ receptors as well as the interaction of theses receptors with nitric oxide and prostanoids. The major finding of this study is that a single course of clinically relevant doses of antenatal betamethasone is associated with specific alterations in vascular reactivity in the adult offspring. The dose of betamethasone administered to the ewe $(0.17 \mathrm{mg} / \mathrm{kg}$ body weight) is equivalent to the $12 \mathrm{mg}$ dose recommended by the National Institutes of Health consensus panel to be used in women threatened with premature labor (17). The alterations in vascular reactivity we report suggest that antenatal steroid treatment results in increased smooth muscle responsiveness and also in endothelial dysfunction, thus they could be a contributing factor for the development of hypertension (5). Limited information exists regarding the long-term effects of prenatal glucocorticoids exposure on arterial blood pressure levels in humans. Furthermore, the association between antenatal glucocorticoid administration and elevations in arterial blood pressure is not a universal finding $(6,18,19)$. In the report of Doyle et al. (6), a small but significant elevation in blood pressure was evident at $14 \mathrm{y}$ of age in a cohort who received betamethasone at an average of $28 \mathrm{wk}$ gestation. In contrast, no elevations in blood pressure were found when antenatal glucocorticoids were administered at an average of 32 wk gestation at either 6 or $30 \mathrm{y}$ of age $(18,19)$. Gestational age at treatment and birth weight are strikingly different in these cohorts and may hold the answer for the different findings. In the Doyle study birth weights ranged between 1000-1500 g whereas in the Dalziel studies birth weights were 1760-2710 (18) and 2343-2505 (19). Our experimental approach rules out the contribution prematurity may have in the cardiovascular alteration observed later in life. Therefore, collectively our previous data (5) and the present findings strongly support that the effects of antenatal glucocorticoids are independent from prematurity.

The depolarizing effect of high concentration potassium chloride is commonly used as a tool for evaluating smooth muscle responsiveness in an agonist-independent manner to remove the confounding effects of receptor density and signal transduction, however, it can still be affected by differences in endothelial function. Our results show that BM-exposed sheep exhibit an increased contractile response to $\mathrm{KCl}$ when the endothelium is removed. This finding suggests that when comparing endothelium-intact arteries, the differences in smooth muscle contractility between control and BM-treated arteries are masked by an increased endothelium-derived relaxant activity. An enhanced response to $\mathrm{KCl}$ in arteries of the betamethasone group was also evident after known vasodilatory pathways were blocked. Nitric oxide and prostanoids affecting vasomotor activity are considered to originate predominantly from endothelium, however, in some vascular beds smooth muscle production of these bioactive molecules is known to occur $(20,21)$. The larger response to $\mathrm{KCl}$ in L-NAME pretreated arteries suggests that, in sheep brachial artery, there may be contribution of the smooth muscle to NO production. Notwithstanding, evidence for a predominant endothelial source for $\mathrm{NO}$ is provided by the increased relaxant response to the endothelium-dependent $\mathrm{NO}$ generator $\mathrm{ACh}$ in arterial segments obtained from BM-treated sheep. With the data at hand, we can only speculate regarding the mechanism underlying the increased responsiveness to the depolarizing effects of $\mathrm{KCl}$. The contractile response to depolarization is mainly dependent on entry of calcium through voltage-gated calcium channel (VDCC). Increased activity of VDCC and decreased activity of the voltage-gated $\mathrm{K}^{+}$channels $\left(\mathrm{K}_{\mathrm{V}}\right)$ have been shown to be present in systemic and pulmonary vessels exposed to hypertension $(22,23)$. However, the changes in the membrane VDCC and $\mathrm{K}_{\mathrm{V}}$ channel population in chronic hypertension can be considered both pathogenic or adaptive in nature $(22,24)$. Therefore, it is plausible that antenatal betamethasone exposure is associated with alterations in ion channels and that increasing the intracellular calcium concentration increases the maximal response to $\mathrm{KCl}$. Vascular smooth muscle hypertrophy may also play a role in the enhanced response to $\mathrm{KCl}$ and its contribution requires further investigation. The endothelin family is composed of three isoforms (ET-1, ET-2, and ET-3). Of these, ET-1 is considered the most important isoform in the regulation of vascular tone (25). ET-1 effects are mediated through activation of the G-proteincoupled receptors $\mathrm{ET}_{\mathrm{A}}$ and $\mathrm{ET}_{\mathrm{B}}$. ET-1 effects are mediated through activation of the G-protein-coupled receptors $\mathrm{ET}_{\mathrm{A}}$ and $\mathrm{ET}_{\mathrm{B}}$. Vascular smooth muscle cells express both $\mathrm{ET}_{\mathrm{A}}$ and $\mathrm{ET}_{\mathrm{B}}$ receptors whereas endothelial cells express only $\mathrm{ET}_{\mathrm{B}}$. The vasoconstrictive effects of ET-1 are mediated by both 
$\mathrm{ET}_{\mathrm{A}}$ and $\mathrm{ET}_{\mathrm{B}}$ in arteries and veins, however, the relative contribution of $\mathrm{ET}_{\mathrm{B}}$ depends on the vascular bed (14). In endothelium, $\mathrm{ET}$ binding to $\mathrm{ET}_{\mathrm{B}}$ receptors induces vasorelaxation through the production of $\mathrm{NO}$ and prostacyclin. As in the case for smooth muscle, endothelial $\mathrm{ET}_{\mathrm{B}}$ expression is also vascular bed-dependent. Our results show that arteries derived from animals exposed to antenatal betamethasone exhibit an enhanced sensitivity to ET-1 stimulation. These data are consistent with the reported effects on ET-1 sensitivity in experiments using different steroids administration protocols. Sheep exposed to maternal betamethasone at 26-28 d gestation have an elevation in blood pressure by 3 mo of age that amplifies later in adult life $(2,9,26,27)$. In this model of fetal programming, coronary artery response to ET-1 was shown to be enhanced in 1-wk newborns and also at 5 mo of age $(2,3)$. Repeated weekly exposure to low doses of maternally administered dexamethasone starting at $103 \mathrm{~d}$ of gestational age resulted in increased sensitivity to ET-1 in skeletal muscle arteries of $119 \mathrm{dGA}$ fetuses, (28) with this alteration persisting postnatally up to $5 \mathrm{mo}$ of age (4). These data supporting an early alteration in the responsiveness to ET-1 suggest that the enhanced sensitivity to ET-1 is most likely a contributing factor in the development of hypertension rather than being a consequence of it. Roghair and colleagues (2) have shown that in the early gestation steroid administration paradigm the increased sensitivity to ET-1 is present at time points in development where no elevations in blood pressure have been reported. In the repeated steroid exposure paradigm, despite the increased sensitivity to ET-1, no elevations in blood pressure were observed (4). Unfortunately, in the studies of Molnar et al., 5 mo was the oldest age studied (4). Thus, it is uncertain whether these animals would develop hypertension once reaching adulthood. Our data also show that removal of the endothelium, which, as expected, increased the response to ET-1 in arteries of control animals, was without effect in arteries of BM-exposed sheep. Similarly, preincubation with L-NAME did not affect the response to ET-1 in arteries of BM-exposed sheep. We have interpreted these observations, at least in part, to represent an uncoupling of the $\mathrm{ET}_{\mathrm{B}}$ receptor from endothelial nitric oxide synthase activation, thus suppressing the counteracting role of endothelial endothelin $\mathrm{ET}_{\mathrm{B}}$ receptors. Preincubation of the arterial segments with submaximal concentrations of an $\mathrm{ET}_{\mathrm{B}}$ antagonist (BQ788) revealed that ET-1 stimulation again had a differential effect in the arterial segments of BM-exposed sheep. In controls, as expected, $\mathrm{ET}_{\mathrm{B}}$ antagonism resulted in an increased sensitivity to ET-1 due to the removal of the ET-1-dependent NO generation. The decreased sensitivity to ET-1 induced by BQ788 preincubation in arteries of BM-exposed sheep suggests that smooth muscle $\mathrm{ET}_{\mathrm{B}}$ receptors have an important contribution in the contractile response. Collectively, our data suggest that antenatal steroid administration has a dual effect on the endothelin system in brachial arteries: 1) endothelial dysfunction with an impairment of endothelin-1 $\mathrm{ET}_{\mathrm{B}}$ receptorinduced release of nitric oxide and 2) an increase contribution of the $\mathrm{ET}_{\mathrm{B}}$ receptor in smooth muscle to the contractile effects of ET-1. In hypertensive humans, a similar endothelin receptor imbalance has also been described (15). Hypertensive patients responded to selective $\mathrm{ET}_{\mathrm{B}}$ blockade with transient vasodilation suggesting that an impairment of $\mathrm{ET}_{\mathrm{B}}$-mediated vasodilation contributes to the elevation in blood pressure in these patients (15). The authors demonstrated that this effect, which was not present in normotensive, was not determined by a nonselective increased vasoconstrictor response.

In summary, our data document alterations in vascular smooth muscle contractile response and endothelial dysfunction in the offspring of sheep treated with clinically relevant doses of betamethasone at a gestational stage when human fetuses are routinely exposed to glucocorticoids if the mother is threatened with premature delivery. Due to the complex mechanisms involved in the genesis and maintenance of elevated blood pressure, further studies are needed to establish whether the changes in vascular reactivity represent a causative mechanism or an adaptive response to an elevation in blood pressure.

\section{REFERENCES}

1. Barker DJ, Fall CH 1993 Fetal and infant origins of cardiovascular disease. Arch Dis Child 68:797-799

2. Roghair RD, Lamb FS, Miller FJ Jr, Scholz TD, Segar JL 2005 Early gestation dexamethasone programs enhanced postnatal ovine coronary artery vascular reactivity. Am J Physiol Regul Integr Comp Physiol 288:R46-R53

3. Roghair RD, Segar JL, Sharma RV, Zimmerman MC, Jagadeesha DK, Segar EM, Scholz TD, Lamb FS 2005 Newborn lamb coronary artery reactivity is programmed by early gestation dexamethasone before the onset of systemic hypertension. Am J Physiol Regul Integr Comp Physiol 289:R1169-R1176

4. Molnar J, Howe DC, Nijland MJ, Nathanielsz PW 2003 Prenatal dexamethasone leads to both endothelial dysfunction and vasodilatory compensation in sheep. J Physiol 547:61-66

5. Figueroa JP, Rose JC, Massmann GA, Zhang J, Acuńa G 2005 Alterations in fetal kidney development and elevations in arterial blood pressure in young adult sheep after clinical doses of antenatal glucocorticoids. Pediatr Res 58:510-515

6. Doyle LW, Ford GW, Davis NM, Callanan C 2000 Antenatal corticosteroid therapy and blood pressure at 14 years of age in preterm children. Clin Sci 98:137-142

7. Dodic M, Baird R, Hantzis V, Koukoulas I, Moritz K, Peers A, Wintour EM 2001 Organs/systems potentially involved in one model of programmed hypertension in sheep. Clin Exp Pharmacol Physiol 28:952-956

8. Wintour EM, Johnson K, Koukoulas I, Moritz K, Tersteeg M, Dodic M 2003 Programming the cardiovascular system, kidney and the brain-a review. Placenta 24:S65-S71

9. Dodic M, Peers A, Coghlan JP, May CN, Lumbers E, Yu Z, Wintour EM 1999 Altered cardiovascular haemodynamics and baroreceptor-heart rate reflex in adult sheep after prenatal exposure to dexamethasone. Clin Sci 97:103-109

10. Manning J, Beutler K, Knepper MA, Vehaskari VM 2002 Upregulation of renal BSC1 and TSC in prenatally programmed hypertension. Am J Physiol Renal Physiol 283:F202-F206

11. Vehaskari VM, Stewart T, Lafont D, Soyez C, Seth D, Manning J 2004 Kidney angiotensin and angiotensin receptor expression in prenatally programmed hypertension. Am J Physiol Renal Physiol 287:F262-F267

12. Segar JL, Lumbers ER, Nuyt AM, Smith OJ, Robillard JE 1998 Effect of antenatal glucocorticoids on sympathetic nerve activity at birth in preterm sheep. Am J Physiol 274:R160-R167

13. Schiffrin EL 1999 Role of endothelin-1 in hypertension. Hypertension 34:876-881

14. Schiffrin EL 2005 Vascular endothelin in hypertension. Vascul Pharmacol 43:19-29

15. Cardillo C, Kilcoyne CM, Waclawiw M, Cannon RO 3rd, Panza JA 1999 Role of endothelin in the increased vascular tone of patients with essential hypertension. Hypertension 33:753-758

16. Mulvany MJ, Halpern W 1977 Contractile properties of small arterial resistance vessels in spontaneously hypertensive and normotensive rats. Circ Res 41:19-26

17. NIH Consensus Development Panel on the Effect of Corticosteroids for Fetal Maturation on Perinatal Outcomes 1995 Effect of corticosteroids for fetal maturation on perinatal outcomes. NIH Consensus Conference. JAMA 273:413-418

18. Dalziel SR, Liang A, Parag V, Rodgers A, Harding JE 2004 Blood pressure at 6 years of age after prenatal exposure to betamethasone: follow-up results of a randomized, controlled trial. Pediatrics 114:e373-e377

19. Dalziel SR, Walker NK, Parag V, Mantell C, Rea HH, Rodgers A, Harding JE 2005 Cardiovascular risk factors after antenatal exposure to betamethasone: 30-year follow-up of a randomised controlled trial. Lancet 365:1856-1862

20. Ward ME, Toporsian M, Scott JA, Teoh H, Govindaraju V, Quan A, Wener AD, Wang G, Bevan SC, Newton DC, Marsden PA 2005 Hypoxia induces a functionally significant and translationally efficient neuronal NO synthase mRNA variant. J Clin Invest 115:3128-3139 
21. Rosenfeld CR, Chen C, Roy T, Liu X 2003 Estrogen selectively up-regulates eNOS and nNOS in reproductive arteries by transcriptional mechanisms. J Soc Gynecol Investig 10:205-215

22. Cox RH, Rusch NJ 2002 New expression profiles of voltage-gated ion channels in arteries exposed to high blood pressure. Microcirculation 9:243-257

23. Yuan JX, Aldinger AM, Juhaszova M, Wang J, Conte JV Jr, Gaine SP, Orens JB, Rubin LJ 1998 Dysfunctional voltage-gated $\mathrm{K}^{+}$channels in pulmonary artery smooth muscle cells of patients with primary pulmonary hypertension. Circulation 98:1400-1406

24. Pesic A, Madden JA, Pesic M, Rusch NJ 2004 High blood pressure upregulates arterial L-type $\mathrm{Ca}^{+}{ }^{+}$channels: is membrane depolarization the signal? Circ Res 94:e97-e104
25. Rubanyi GM, Polokoff MA 1994 Endothelins: molecular biology, biochemistry, pharmacology, physiology, and pathophysiology. Pharmacol Rev 46:325-415

26. Dodic M, Wintour EM 1994 Effects of prolonged ( $48 \mathrm{~h}$ ) infusion of cortisol on blood pressure, renal function and fetal fluids in the immature ovine foetus. Clin Exp Pharmacol Physiol 21:971-980

27. Dodic M, May CN, Wintour EM, Coghlan JP 1998 An early prenatal exposure to excess glucocorticoid leads to hypertensive offspring in sheep. Clin Sci 94:149-155

28. Molnar J, Nijland MJ, Howe DC, Nathanielsz PW 2002 Evidence for microvascular dysfunction after prenatal dexamethasone at $0.7,0.75$, and 0.8 gestation in sheep. Am J Physiol Regul Integr Comp Physiol 283:R561-R567 